\title{
Leading the Nation in Clean Energy Deployment
}

The U.S. Department of Energy (DOE) is pursuing an aggressive, scalable, and replicable strategy to accelerate market adoption of clean energy solutions to power homes, businesses, and vehicles. Using the comprehensive Integrated Deployment approach developed by the National Renewable Energy Laboratory (NREL), DOE partners with communities, cities, states, federal agencies, and territories to identify and implement a variety of efficiency and renewable energy technology solutions.
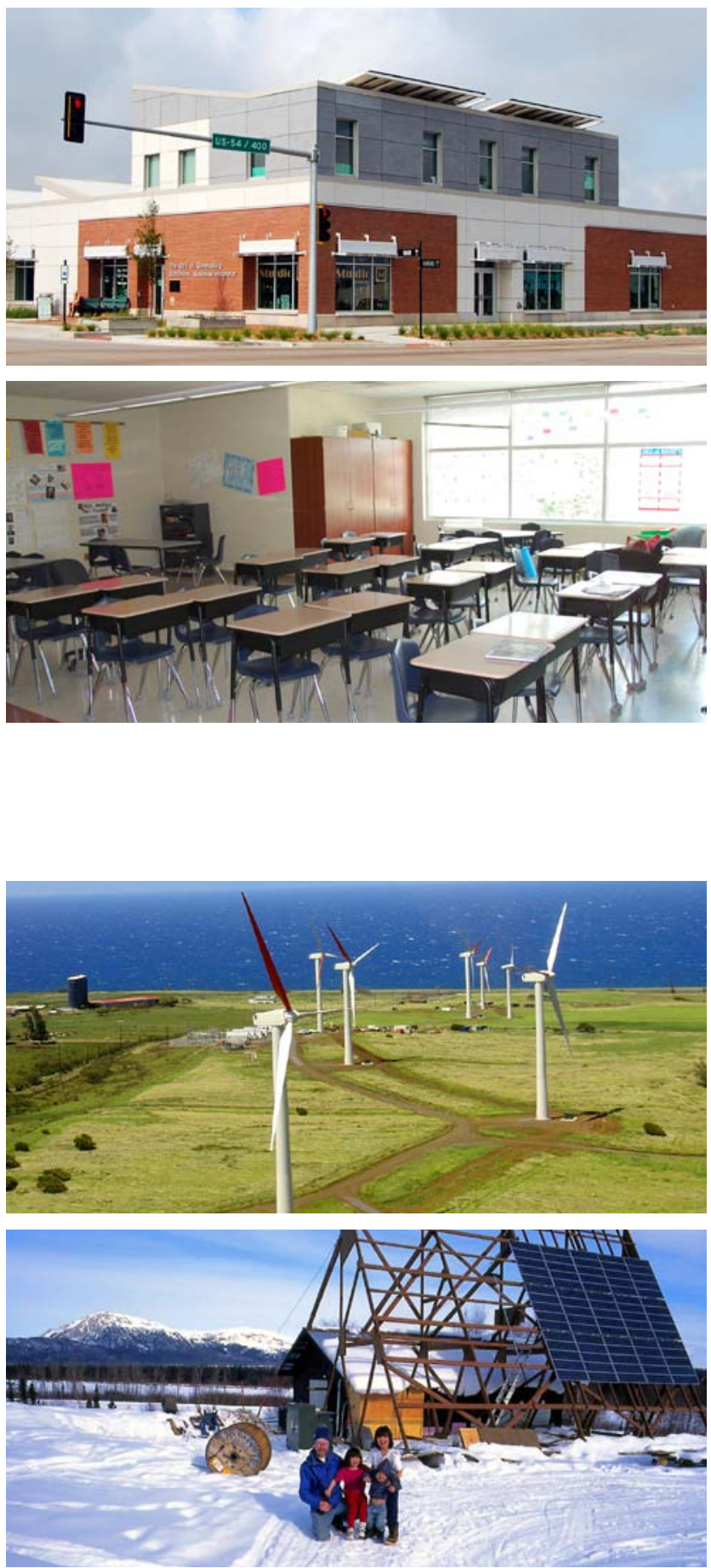

\section{Disaster Recovery}

DOE and NREL technical experts have helped communities like Greensburg, Kansas, and New Orleans, Louisiana, successfully rebuild following disaster by providing assistance with sustainable community planning, forward-thinking policy development, and energy modeling and monitoring. The cities showcase energy-saving best practices and renewable energy technology use that can be replicated not only in other communities recovering from disaster, but any location focused on sustainability.

Greensburg has rebuilt homes that on average use $40 \%$ less energy than code achieving the highest per-capita concentration of LEED (Leadership in Energy and Environmental Design) certified buildings in the United States, with 13 showcase buildings saving a combined total of $\$ 200,000$ in energy costs annually. The town has also implemented LED lights and 12.5 megawatts of wind power.

New Orleans has built four new K-12 schools that are 30\% more energy efficient than code, using solar photovoltaics to generate a combined total of 25 kilowatts of power and identifying more than $\$ 1.9$ million in utility bill savings for approximately 50 schools that survived Hurricanes Katrina and Rita. The city is also using biodiesel-fueled city buses and propane hybrid airport shuttles.

\section{Statewide Activities}

DOE and NREL experts have provided technical assistance to help states such as Alaska and Hawaii identify ways to reduce fossil fuel use and implement clean energy technology solutions, which can serve as a model for other locations with similar climates and energy challenges.

Through the Hawaii Clean Energy Initiative, a public-private partnership between DOE and the state of Hawaii, DOE and NREL coordinate with the state, the private sector, county governments, and local communities to support Hawaii's goal of achieving 70\% clean energy by 2030 .

In Alaska, DOE and NREL actively provide technology and project deployment expertise to ensure success in various areas, including village diesel fuel reduction, residential energy efficiency, and policy analysis. 


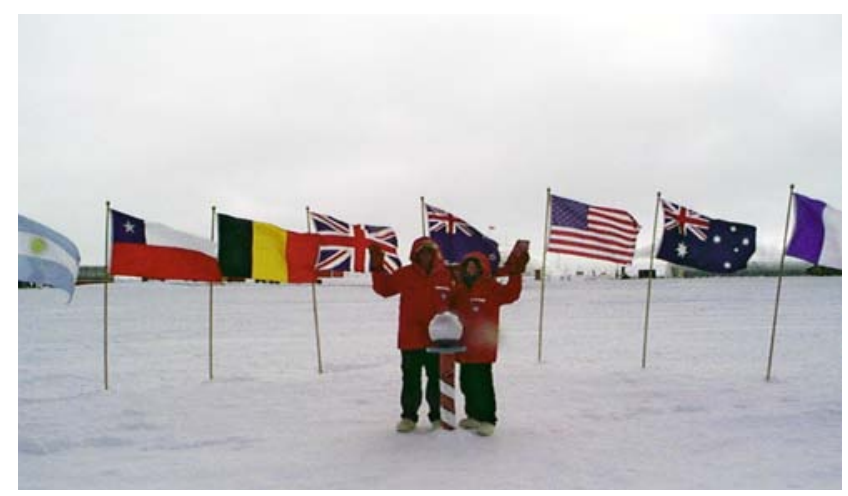

\section{Federal Agency Support}

DOE and NREL are helping the nation's largest energy consumer - the federal government - pursue aggressive and integrated solutions to energy independence.

For example, DOE and the U.S. Department of Defense have teamed up to help military installations across the country reduce their reliance on local energy grids by producing as much energy on-site as their buildings, facilities, and fleet vehicles consume.

At polar sites, DOE and NREL are working with the National Science Foundation to identify solutions that not only reduce the environmental impact of research stations, but also provide cost-effective and reliable energy to support research needs.

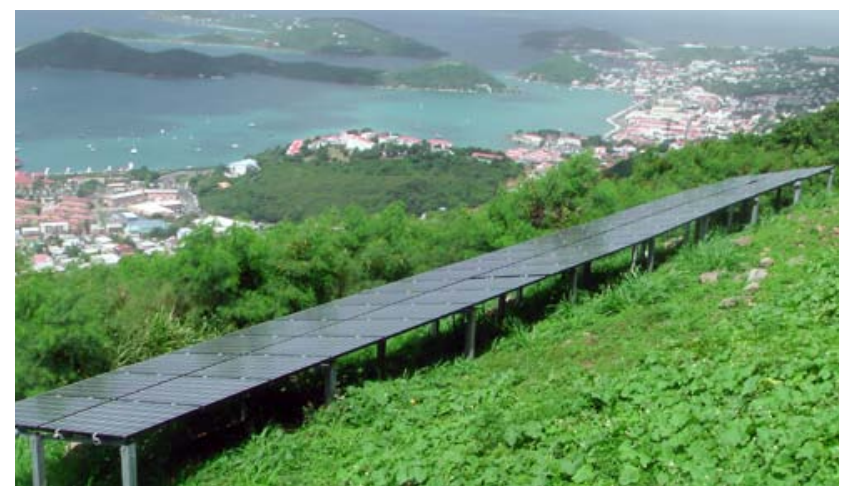

\section{Island Activities}

Through partnerships such as Energy Development in Island Nations, which includes Iceland, New Zealand, and the United States, DOE and NREL collaborate to support clean energy initiatives in places like the U.S. Virgin Islands to increase energy security and sustainability by reducing dependence on imported fossil fuels.

Working directly with island governments, utilities, business leaders, and grassroots supporters, DOE and NREL guide clean energy strategy and development to help islands adopt energy efficiency measures and tap into indigenous renewable resources using a holistic model that can be replicated by islands worldwide.

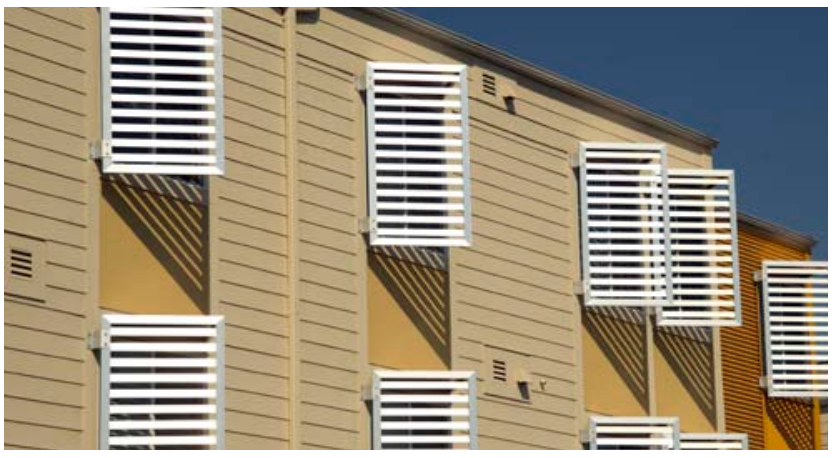

\section{Community Renewable Energy Deployment}

Creating jobs, reducing carbon emissions at the local level, and providing examples for replication are just some of the goals of the DOE Community Renewable Energy Deployment effort funded by the American Recovery and Reinvestment Act of 2009.

Through the DOE grant, NREL is providing technical assistance on renewable energy technology planning and implementation for projects in five communities located in California, Colorado, Vermont, and Wisconsin.

\section{More Information}

For more information about the Integrated Deployment approach and example projects, visit www.eere.energy.gov/deployment. 